\title{
ESTIOLAMENTO, INCISÃO NA BASE DA ESTACA E USO DE AIB NO ENRAIZAMENTO DE ESTACAS HERBÁCEAS DE CARAMBOLEIRA ${ }^{1}$
}

\author{
DÉBORA COSTA BASTOS², JOÃO ALEXIO SCARPARE FILHO ${ }^{3}$, JÚNIOR CÉSAR FATINANSI ${ }^{4}$, RAFAEL PIO ${ }^{5}$
}

\begin{abstract}
RESUMO - Este trabalho foi desenvolvido com o objetivo de verificar a influência do estiolamento, técnica de incisão na base da estaca e aplicação do ácido indolbutírico (AIB) no enraizamento de estacas herbáceas de caramboleira. As estacas foram padronizadas com um par de folhas inteiras e $15 \mathrm{~cm}$ de comprimento. O experimento foi conduzido em delineamento estatístico inteiramente casualizado, em arranjo fatorial $3 \times$ 4 , onde os fatores estudados foram técnicas aplicadas nas estacas (estiolamento e ferimento na base) e diferentes concentrações de AIB (0;2.000; 4.000 e 6.000 mg L-1). As estacas herbáceas foram utilizadas como tratamento-controle. O estiolamento foi realizado 45 dias antes da retirada da estaca no ramo, envolvendo-se a base da futura estaca com fita plástica preta. A incisão na base da estaca foi realizada no preparo das mesmas, através de dois cortes na base. As estacas foram mantidas em câmara de nebulização intermitente e, após 75 dias, avaliaram-se as porcentagens de estacas enraizadas, de sobrevivência e de calos formados, comprimento da maior raiz por estaca e as massas frescas e secas das raízes. Concluiu-se que estacas herbáceas sem a utilização do estiolamento, do ferimento na base da estaca e da aplicação de AIB apresentaram os melhores resultados de enraizamento (50,3\%).
\end{abstract}

Termos para indexação: carambola, estiolamento e propagação.

\section{SHADING, BASE INCISION OF CUTTINGS AND USE OF IBA IN ROOTING OF STAR FRUIT HERBACEOUS CUTTINGS}

ABSTRACT - This paper was carried out with the objective to verify the influence of shading, lesion in base cuttings and application of Indolbutyric acid (IBA) in rooting herbaceous star fruit cuttings. The cuttings were patronized with two leaves, and $15 \mathrm{~cm}$ of length. The experimental design was completely randomized, with the factorial $3 \times 4$, where the studied factors were techniques applied in the cuttings (shading and base incision ) and different concentration of IBA $\left(0 ; 2,000 ; 4,000\right.$ and $\left.6,000 \mathrm{mg} \mathrm{L}^{-1}\right)$. The herbaceous cuttings were used as treatment controls. The shading was accomplished 45 days before the retreat of the cuttings in the branch, wrapping up the base of the future cuttings with black plastic ribbon and the base incision of the cuttings was accomplished in the preparation of the same ones, through two cuts in the base. The cuttings were maintained in chamber under intermittent mist and after 75 days, the rooting percentage, survival percentage, callus formation percentage, length of roots per cuttings, and fresh and dry weight of roots were evaluated. It was concluded that herbaceous cuttings without utilization of shading, lesion in base cuttings and application of IBA showed the best results of rooting $(50.3 \%)$.

Index terms: star fruit, shading and propagation.

\section{INTRODUÇÃO}

A carambola (Averrhoa carambola L.) é uma fruta exótica pertencente à família Oxalidaceae que tem como centro de origem o Sudeste Asiático (Nakasone \& Paul, 1998). No Brasil, principalmente no Estado de São Paulo, essa cultura está em expansão com pomares sendo formados a partir de plantas obtidas por sementes, provenientes de cultivares originárias da Flórida e da Malásia, e, em alguns casos, através da enxertia. Porém, são poucas as informações sobre o cultivo da planta (propagação, produção de mudas e frutos).

A produção de mudas da caramboleira pode ser realizada através da utilização de sementes ou de métodos vegetativos. A utilização de sementes no processo de multiplicação é um método inviável devido à ocorrência de variabilidade genética e ao maior período para iniciar a produção, normalmente entre 2 e 3 anos, devendo ser utilizada apenas para a formação dos porta-enxertos. A propagação, que geralmente é através da enxertia (borbulhia ou garfagem), é o método mais utilizado comercialmente, entretanto apresenta limitações como maior mão-de-obra e alto custo. Dessa maneira, a propagação por estacas pode proporcionar mudas de qualidade, fixando características agronômicas desejáveis, de forma eficiente.

$\mathrm{Na}$ estaquia, muitas vezes, a aplicação de reguladores de crescimento é decisiva para a formação de raízes e tem por finalidade aumentar a porcentagem de estacas que formam raízes, acelerar sua iniciação, aumentar o número e a qualidade das raízes formadas e uniformizar o enraizamento (Fachinello et al., 1995).

$\mathrm{O}$ grupo de reguladores de crescimento usado com maior freqüência é o das auxinas (Hinojosa, 2000). De acordo com Hartmann et al. (2002), as auxinas são as substâncias mais importantes, que desempenham maiores funções no enraizamento de estacas. Entre as principais funções biológicas das auxinas, pode-se citar o crescimento de órgãos, especialmente as raízes. A auxina de presença natural é sintetizada principalmente em gemas apicais e em folhas jovens e, de maneira geral, move-se através da planta, do ápice para a base. Uma das formas mais comuns de favorecer o balanço hormonal para o enraizamento é a aplicação exógena de reguladores de crescimento, tais como o ácido indolbutírico (AIB) (Pasqual et al., 2001).

O AIB, por ser estável a fotodegradação e possibilitar boa capacidade de enraizamento, tem sido utilizado em estacas de várias espécies, principalmente naquelas que apresentam dificuldade em emitir raízes (Fachinello et al., 1995). Bastos (2002) observou aumento na porcentagem de enraizamento de estacas herbáceas de caramboleira (67\%) com a aplicação de $5.000 \mathrm{mg} \mathrm{L}^{-1}$ de AIB. Em estacas de caquizeiro, Nishimoto (1994) verificou aumento na capacidade de enraizamento, obtendo-se em seu estudo 18,9\% para a cultivar Pomelo, 15,6\% para a cultivar Rama Forte e $0,8 \%$ para a cultivar Taubaté.

$\mathrm{O}$ uso de estiolamento e da aplicação de reguladores de crescimento, ou sinergismo das duas técnicas, tem apresentado bons resultados para espécies de difícil enraizamento. Segundo Hartmann et al. (2002), o estiolamento vem a ser o desenvolvimento de brotos, ramos ou parte dos ramos em ausência de luz. Bastos \& Scarpare Filho (2003), em estudos prévios utilizando as técnicas de estiolamento e ferimento na base, em estacas de caramboleira, observaram melhores resultados de enraizamento em estacas herbáceas que não foram estioladas nem feridas na base (tratamento controle). Maior porcentagem de enraizamento em estacas de guaranazeiros foram obtidos devido ao

\footnotetext{
${ }^{1}$ (Trabalho 197/2004). Recebido: 21/12/2004. Aceito para publicação: 27/06/2005. Parte da Tese do primeiro autor. Apoio financeiro Fapesp.

${ }^{2}$ Eng $^{\circ}$. Agrônoma, M.Sc., Doutoranda em Fitotecnia, Depto. de Produção Vegetal, Escola Superior de Agricultura “Luiz de Queiroz”, Universidade de São Paulo

- ESALQ/USP. Av. Pádua Dias, 11 13418-900, Piracicaba-SP. Autora para correspondência: dcbastos@esalq.usp.br.

${ }^{3}$ Eng $^{\circ}$. Agrônomo, D.Sc., Professor do Depto. de Produção Vegetal, ESALQ/USP, Piracicaba-SP.

${ }^{4}$ Eng $^{\circ}$. Agrícola, Mestrando em Ciências - CENA/USP, Piracicaba-SP.

${ }^{5}$ Eng $^{0}$.Agrônomo, M.Sc., Doutorando em Fitotecnia, ESALQ/USP, Pesquisador do IAC - Jundiaí-SP. rafaelpio@iac.sp.gov.br
} 
estiolamento de ramos com fita preta plástica e adesiva, ainda na planta, na base da futura estaca (Rodrigues \& Luchesi, 1987). No entanto, para estacas de laranja Pêra, melhores resultados de enraizamento foram obtidos com o estiolamento prévio dos ramos aliado com a aplicação de AIB (Sampaio, 1989).

Além do estiolamento e da aplicação de reguladores de crescimento, outras técnicas podem ser utilizadas para favorecer o enraizamento das estacas, dentre as quais, a injúria mecânica, que consiste de incisões (ferimentos) na base das estacas (Hartmann et al., 2002). Segundo Howard et al. (1984), as incisões expõem o câmbio e a região do córtex, aumentando assim a interação com o regulador vegetal. As lesões nos tecidos estimulam a divisão celular, produzindo primórdios radiculares, possivelmente devido ao acúmulo de carboidratos, auxinas e síntese de etileno nessa região lesada (Hartmann et al., 2002).

Este trabalho foi desenvolvido com o objetivo de estudar o enraizamento de estacas herbáceas de caramboleira aliados as técnicas de estiolamento e incisão (ferimento) na base das estacas, juntamente com a aplicação de ácido indolbutírico.

\section{MATERIAL E MÉTODOS}

As estacas foram obtidas de plantas de caramboleiras com 15 anos de idade, oriundas de pomares comerciais localizados em JaguariúnaSP. Uma parte dos ramos herbáceos das plantas-matrizes foi submetida ao estiolamento, utilizando-se de fita plástica preta na base da futura estaca, pelo período de 45 dias. Posteriormente, os ramos foram coletados para a retirada das estacas e estas padronizadas, com um par de folhas inteiras, $15 \mathrm{~cm}$ de comprimento e $0,8 \mathrm{~cm}$ de diâmetro. Uma parte das estacas sofreu incisões mecânicas na base com auxílio de um canivete. Em seguida, as estacas foram imersas em diferentes concentrações de AIB $\left(0 ; 2.000 ; 4.000\right.$ e $\left.6.000 \mathrm{mg} \mathrm{L}^{-1}\right)$, por cinco segundos. As estacas foram colocadas em bandejas plásticas ( $46 \mathrm{~cm} \times 9 \mathrm{~cm} \times 28 \mathrm{~cm})$, preenchidas com substrato vermiculita de grânulos médios e acondicionadas em câmara de nebulização intermitente (temperatura de $25 \pm 5^{\circ} \mathrm{C}$, UR média de $72 \%$, tempo de aspersão de 20 segundos, em intervalos de 10 minutos).

Adotou-se o delineamento estatístico inteiramente casualizado, em arranjo fatorial $3 \times 4$, onde os fatores estudados foram as técnicas aplicadas nas estacas (estiolamento e ferimento - incisões na base) e concentrações de AIB $\left(0 ; 2.000 ; 4.000\right.$ e $\left.6.000 \mathrm{mg} \mathrm{L}^{-1}\right)$, com quatro repetições e 10 estacas por unidade experimental. Foram utilizadas estacas herbáceas como tratamento-controle.

Após 75 dias, avaliaram-se a porcentagem de estacas enraizadas, de sobrevivência e de calos formados, o comprimento da maior raiz por estaca e as massas frescas e secas das raízes. Para efeito da análise estatística, os dados em porcentagem foram transformados em arc-sen $\sqrt{x+0,5}$. Os dados foram submetidos à análise de variância e as médias ao teste Scott-Knott (1974), ao nível de 1\% de probabilidade (Gomes, 2000). As análises foram realizadas pelo programa computacional Sistema para Análise de Variância - SISVAR (Ferreira, 2000).

\section{RESULTADOS E DISCUSSÃO}

Pode-se verificar o efeito significativo do tipo de estaca aliado ao AIB para a porcentagem de estacas enraizadas (Tabela 1). Estacas herbáceas sem a utilização do regulador (50,3\%) e com $2.000 \mathrm{mg} \mathrm{L}^{-1} \mathrm{de}$ AIB $(43,5 \%)$ apresentaram melhores resultados de enraizamento. Em relação às estacas herbáceas estioladas e herbáceas com ferimento, não houve diferença significativa nas concentrações de $4.000(29,3 \%)$ e $6.000(23,1 \%) \mathrm{mg} \mathrm{L}^{-1} \mathrm{de}$ AIB. Estacas estioladas apresentaram diferenças estatísticas significativas nas demais concentrações, sendo estas de maior porcentagem de enraizamento.

Nesse caso, o uso do estiolamento e incisões na base das estacas parece não ter contribuído para um maior enraizamento, uma vez que foi necessária a utilização de maiores concentrações de AIB para promover resultados semelhantes ao tratamento-controle. Estes resultados estão de acordo com os obtidos por Figueiredo et al. (1995), que consideraram desnecessária a utilização de AIB no enraizamento de estacas estioladas de goiabeira serrana e por Costa Jr. (2000) no enraizamento de estacas estioladas de goiabeira cultivar 'Rica'. Souza et al. (1995), trabalhando com o enraizamento de estacas de ameixeira cultivar 'Reubennel', não constataram diferenças significativas entre o enraizamento das estacas com e sem ferimento.

Em relação à sobrevivência das estacas, esta foi maior em estacas herbáceas com ferimento tratadas com $6.000 \mathrm{mg} \mathrm{L}^{-1}$ de AIB $(68,5 \%)$. Entretanto, não houve diferença significativa quando comparada às estacas herbáceas, sem o tratamento com o regulador $(59,7 \%)$ (Tabela 1). De acordo com esses resultados, pode-se observar a relação positiva entre o maior potencial de enraizamento e de sobrevivência, fato semelhante ao observado por Nachtigal (1999), em estacas de pessegueiro, que concluiu haver relação positiva entre a porcentagem de sobrevivência e de enraizamento, principalmente na utilização de estacas herbáceas.

Para a porcentagem de estacas com calos, estacas herbáceas sem tratamento com o regulador apresentaram maior porcentagem $(59,7 \%)$, não diferindo estatisticamente de estacas estioladas e com ferimento tratadas com 4.000 e $6.000 \mathrm{mg} \mathrm{L}^{-1}$ de AIB (Tabela 2).

TABELA 1 - Médias das porcentagens de enraizamento e sobrevivência de estacas de caramboleira, em função do tratamento com AIB, e tipos de estacas. ESALQ/USP, Piracicaba-SP, 2003.

\begin{tabular}{|c|c|c|c|c|c|c|}
\hline \multirow{2}{*}{$\begin{array}{c}\mathrm{AIB} \\
\left(\mathrm{mg} \mathrm{L}^{-1}\right)\end{array}$} & \multicolumn{3}{|c|}{$\begin{array}{l}\text { Porcentagem de Enraizamento } \\
\end{array}$} & \multicolumn{3}{|c|}{ Porcentagem de Sobrevivência } \\
\hline & Herbácea & Herbácea Estiolada & Herbácea Ferimento & Herbácea & Herbácea Estiolada & Herbácea Ferimento \\
\hline $\mathbf{0}$ & $50,3 \mathrm{Aa}$ & $22,3 \mathrm{Bab}$ & $12,8 \mathrm{Ba}$ & $59,7 \mathrm{Aa}$ & $21,6 \mathrm{Bb}$ & $47,1 \mathrm{Abc}$ \\
\hline 2000 & $43,4 \mathrm{Aa}$ & $10,3 \mathrm{Bb}$ & $19,1 \mathrm{Ba}$ & 46,4 Aab & $31,6 \mathrm{Aab}$ & 33,2 Ac \\
\hline 4000 & $9,0 \mathrm{Bb}$ & $29,3 \mathrm{Aa}$ & $26,4 \mathrm{Aa}$ & $30,6 \mathrm{Bbc}$ & $42,3 \mathrm{ABab}$ & $58,8 \mathrm{Aab}$ \\
\hline 6000 & $12,8 \mathrm{Ab}$ & $23,1 \mathrm{Aab}$ & $23,5 \mathrm{Aa}$ & $17,7 \mathrm{Cc}$ & $45,3 \mathrm{Ba}$ & $68,5 \mathrm{Aa}$ \\
\hline cv (\%) & & 61,05 & & & 49,26 & \\
\hline
\end{tabular}

*As médias seguidas de mesma letra, maiúsculas na linha e minúsculas na coluna, não diferem entre si, pelo teste de Tukey, a 5\% de probabilidade.

TABELA 2 - Médias das porcentagens de calos e comprimento da maior raiz de estacas de caramboleira, em função do tratamento com AIB, e tipos de estacas. ESALQ/USP, Piracicaba-SP, 2003.

\begin{tabular}{|c|c|c|c|c|c|c|}
\hline \multirow{2}{*}{$\begin{array}{c}\text { AIB } \\
\left(\mathrm{mg} \mathrm{L}^{-1}\right)\end{array}$} & \multicolumn{3}{|c|}{$\begin{array}{l}\text { Porcentagem de Calos Formados } \\
\end{array}$} & \multicolumn{3}{|c|}{ Comprimento da Maior Raiz $(\mathrm{cm})$} \\
\hline & Herbácea & Herbácea Estiolada & Herbácea Ferimento & Herbácea & Herbácea Estiolada & Herbácea Ferimento \\
\hline $\mathbf{0}$ & $59,7 \mathrm{Aa}$ & $21,6 \mathrm{Bb}$ & $47,1 \mathrm{Bbc}$ & $13,77 \mathrm{Aa}$ & $6,73 \quad \mathrm{ABab}$ & $4,75 \mathrm{Ba}$ \\
\hline 2000 & $46,4 \mathrm{Aab}$ & $31,6 \mathrm{Bab}$ & $33,2 \mathrm{Bc}$ & $14,03 \mathrm{Aa}$ & $2,83 \mathrm{Bb}$ & $8,37 \mathrm{ABa}$ \\
\hline 4000 & $30,6 \mathrm{Bbc}$ & $42,3 \mathrm{ABab}$ & $58,8 \mathrm{Aab}$ & $1,12 \mathrm{Bb}$ & $13,12 \mathrm{Aa}$ & $6,92 \mathrm{ABa}$ \\
\hline 6000 & $17,7 \mathrm{Bc}$ & $45,3 \mathrm{Aa}$ & 68,5 Aa & 4,88 & $5,10 \quad \mathrm{Aab}$ & $8,73 \mathrm{Aa}$ \\
\hline cv (\%) & & 48,97 & & & 94,85 & \\
\hline
\end{tabular}

*As médias seguidas de mesma letra, maiúsculas na linha e minúsculas na coluna, não diferem entre si, pelo teste de Tukey, a $5 \%$ de probabilidade. 
TABELA 3 - Médias das massas frescas e secas das raízes de estacas de caramboleira, em função do tratamento com AIB, e tipos de estacas. ESALQ/ USP, Piracicaba-SP, 2003.

\begin{tabular}{|c|c|c|c|c|c|c|}
\hline \multirow{2}{*}{$\begin{array}{c}\text { AIB } \\
\left(\mathrm{mg} \mathrm{L}^{-1}\right)\end{array}$} & \multicolumn{3}{|c|}{ Massa Fresca das Raízes (g) } & \multicolumn{3}{|c|}{ Massa Seca das Raízes (g) } \\
\hline & Herbácea & Herbácea Estiolada & Herbácea Ferimento & Herbácea & Herbácea Estiolada & Herbácea Ferimento \\
\hline $\mathbf{0}$ & $1,27 \mathrm{Aa}$ & $0,88 \mathrm{ABa}$ & $0,05 \mathrm{Ba}$ & $0,30 \mathrm{Aa}$ & $0,14 \mathrm{ABab}$ & $0,03 \mathrm{Ba}$ \\
\hline 2000 & $1,30 \mathrm{Aa}$ & $0,02 \mathrm{Ba}$ & $0,14 \mathrm{Ba}$ & $0,28 \mathrm{Aa}$ & $0 \quad \mathrm{Bb}$ & $0,11 \mathrm{ABa}$ \\
\hline 4000 & $0 \quad \mathrm{Ab}$ & $0,74 \mathrm{Aa}$ & $0,24 \mathrm{Aa}$ & $0 \quad \mathrm{Bb}$ & $0,24 \mathrm{Aa}$ & 0, hl $\mathrm{AB}$ \\
\hline 6000 & $0,15 \mathrm{Aab}$ & $0,25 \mathrm{Aa}$ & $0,23 \mathrm{Aa}$ & $0,03 \mathrm{Ab}$ & $0,07 \mathrm{Aab}$ & $0,14 \mathrm{Aa}$ \\
\hline cv (\%) & & 145,57 & & & 175,22 & \\
\hline
\end{tabular}

*As médias seguidas de mesma letra, maiúsculas na linha e minúsculas na coluna, não diferem entre si, pelo teste de Tukey, a 5\% de probabilidade.

O tipo de preparo da estaca necessitou de elevada concentração de AIB para promover resultados semelhantes às estacas sem nenhum preparo, que ainda não necessitaram da utilização do regulador para promover bons resultados. Verifica-se ainda resultado semelhante para o comprimento da maior raiz (Tabela 2), onde estacas herbáceas sem a utilização do regulador e com $2.000 \mathrm{mg} \mathrm{L}^{-1}$ de AIB $(13,77)$ apresentaram melhores resultados, apenas não diferindo em relação às estacas herbáceas estioladas com $4.000 \mathrm{mg} \mathrm{L}^{-1}(13,12) \mathrm{e}$ herbáceas com ferimento tratadas com $6.000 \mathrm{mg} \mathrm{L}^{-1}$ de AIB $(8,73)$.

Esses resultados mostram que o tratamento que obteve maior porcentagem de enraizamento também foi o que favoreceu maior comprimento da raiz, demonstrando haver correlação positiva entre essas duas características analisadas. De maneira semelhante, Reis et al. (2000), trabalhando com estacas de pereira, observaram que as estacas sem estiolamento e sem tratamento com AIB apresentaram melhores resultados de enraizamento e comprimento das raízes. Hansen \& Potter (1997), em estacas de macieira, verificaram que os melhores resultados para enraizamento foram obtidos em estacas não-estioladas. De acordo com esses autores, os resultados obtidos neste estudo deixam claro que alguns fatores aumentaram a facilidade de enraizamento das testemunhas dessas espécies, nos quais se incluem a condição fisiológica da planta matriz, a maturidade do material utilizado, além da época do ano em que foram coletadas as estacas (Maynard \& Bassuk, 1996).

Para a massa fresca das raízes, estacas herbáceas sem o tratamento com o regulador $(1,27)$ e com $2.000 \mathrm{mg} \mathrm{L}^{-1}$ de AIB $(1,30)$ apresentaram melhores resultados, não diferindo estatisticamente em relação às estacas herbáceas estioladas e com ferimento tratadas com 4.000 e $6.000 \mathrm{mg} \mathrm{L}^{-1}$ de AIB. De maneira semelhante, melhores resultados para a massa seca das raízes foram constatados com estacas herbáceas sem o tratamento com o regulador e com $2.000 \mathrm{mg} \mathrm{L}^{-1}$ de AIB, estacas estioladas com $4.000 \mathrm{mg} \mathrm{L}^{-1}$ de AIB e estacas com ferimento na base com $6.000 \mathrm{mg} \mathrm{L}^{-1}$ de AIB (Tabela 3).

Esses resultados mostram haver relação positiva entre a capacidade de enraizamento, comprimento da raiz e massa fresca e seca das raízes, entre os tratamentos estudados. Resultados semelhantes foram observados por Souza et al. (1995), que concluíram que o ferimento na base da estaca, juntamente com a aplicação de AIB, não foi suficiente para induzir o enraizamento das estacas de ameixeira cultivar 'Reubennel'.

\section{CONCLUSÕES}

- A utilização do estiolamento, do ferimento na base da estaca e do AIB não influenciou positivamente no enraizamento das estacas de caramboleira. Estacas herbáceas sem nenhum tratamento apresentaram melhores potenciais de enraizamento (50,3\%);

\section{REFERÊNCIAS}

BASTOS, D.C. Efeito da época de coleta, estádio do ramo e do tratamento com IBA no enraizamento de estacas de caramboleira (Averrhoa carambola L.). 2002. 75f. Dissertação (Mestrado em Agronomia) Faculdade de Ciências Agrárias e Veterinárias, Universidade
Estadual Paulista, Jaboticabal, 2002.

BASTOS, D.C.; SCARPARE FILHO, J.A. Estiolamento, ferimento e uso de IBA no enraizamento de estacas herbáceas de caramboleira (Averrhoa carambola L.). In: ANNUAL MEETING OF THE INTERAMERICAN SOCIETY FOR TROPICAL HORTICULTURE, 49., 2003: Fortaleza, CE. Resumos...Fortaleza: Embrapa Agroindústria tropical, 2003.p.92.

COSTA JR, W.H. da Enraizamento de estacas de goiabeiras: influência de fatores fisiológicos e mesológicos. 2000. 66f. Dissertação (Mestrado em Agronomia) - Escola Superior de Agricultura "Luiz de Queiroz”, Universidade de São Paulo, Piracicaba, 2000.

FACHINELLO, J.C.; HOFFMANN, A.; NACHTIGAL, J.C.; KERSTEN, E.; FORTES, G.R.L. Propagação de plantas frutíferas de clima temperado. Pelotas: UFPel, 1995. 179p.

FERREIRA, D. F. Análise estatística por meio do SISVAR (Sistema para Análise de Variância) para Windows versão 4.0. In: REUNIÃO ANUAL DA REGIÃO BRASILEIRA DA SOCIEDADE INTERNACIONAL DE BIOMETRIA, 45., 2000, São Carlos. Anais... São Carlos: UFSCar, 2000. p. 255-258.

FERREIRA, R.C. Efeito de auxinas e sacarose no enraizamento de estacas herbáceas de acerola (Malpighia glabra L.). 1994. $64 \mathrm{f}$. Monografia (Graduação em Agronomia) - Faculdade de Ciências Agrárias e Veterinárias, Universidade Estadual Paulista, Jaboticabal, 1994.

FIGUEIREDO, S.L.B.; KERSTEN, E.; SCHUCH, M.W. Efeito do estiolamento parcial e do ácido indolbutírico no enraizamento de estacas de ramos de goiabeira serrana (Feijoa sellowiana, Berg). Scientia Agricola, Piracicaba, v. 52, n. 1, p. 167-171, 1995.

GOMES, F. P. Curso de estatística experimental. 14. ed. Piracicaba: USP/ESALQ, 2000. 477p.

HANSEN, O.B.; POTTER, J.R. Rooting of apple, Rhododendron, and Moutain Laurel cuttings from stock plants estiolated under two temperatures. HortScience, Alexandria, v.32, n.2, p.304-306, 1997.

HARTMANN, H. T.; KESTER, D. E.; DAVIES JUNIOR, F. T.; GENEVE, R. L. Plant propagation: principles and practices. $7^{\text {th }}$. ed. New Jersey: Prentice Hall, 2002. 880 p.

HINOJOSA, G. F. Auxinas. In: CID, L.P.B. Introdução aos hormônios vegetais. Brasília: EMBRAPA, 2000. p. 15-54.

HOWARD, B.H.; HARRISON-MURRAY, R.S.; MALKENZIE, K.A.D. Rooting responses to wouding winter cutting of "EM-26" apple rootstock. Journal of Horticultural Science, Ashford, v. 59, n. 2, p. 131-139, 1984.

MAYNARD, B.K.; BASSUK, N.L. Effects of stock plant etiolation, shading, banding, and shoot development on histology and cutting propagation of Carpirus betulus L. fastigiata. Journal of American Society for Horticultural Science, Madison, v.121, n.5, p.853-860, 1996.

NACHTIGAL, J.C. Obtenção de porta-enxertos 'Okinawa' e de mudas de pessegueiro (Prunus persica (L.) Batsch) utilizando métodos de propagação vegetativa. 1999. $165 \mathrm{f}$. Tese (Doutorado em Agronomia) - Faculdade de Ciências Agrárias e Veterinárias, Universidade Estadual Paulista, Jaboticabal, 1999.

NAKASONE, H.Y.; PAULL, R.E. Tropical fruits crop production science in horticulture. New york: Cab International, 1998. 445p. 
NISHIMOTO, C. H. Efeito do ácido indolbutírico no enraizamento de estacas herbáceas de caqui (Diospyrus kaki L.). 1994. $51 \mathrm{f}$. Monografia (Graduação em Agronomia) - Universidade Estadual Paulista, Faculdade de Ciências Agrárias e Veterinárias, Jaboticabal.

PASQUAL, M.; CHALFUN, N. N. J.; RAMOS, J. D.; VALE, M. R. do; SILVA, C. R. de R. e. Fruticultura Comercial: propagação de plantas frutíferas. Lavras: UFLA/FAEPE, 2001. 137p.

REIS, J.M.R.; CHALFUN, N.N.J.; LIMA, L.C.O.; LIMA, L.C. Efeito do estiolamento e do ácido indolbutírico no enraizamento de estacas do porta-enxerto Pyrus calleryana Dene. Ciência Agrotécnica, Lavras, v. 24, n. 4, p. 931-938, 2000.

RODRIGUES, J.E.; LUCHESI, A.A. Propagação vegetativa do guaranazeiro (Paullinia cupana (Mart.) Ducke) através de estacas induzidas (capeadas) e com ácido indolbutírico. Anais da Escola Superior de Agricultura “Luiz de Queiroz", Piracicaba, v. 44, n. 1, p. $1-20,1987$.
SAMPAIO, V.R. Enraizamento de estacas de laranja Pêra (Citrus sinensis Osbeck L.). In: CONGRESSO BRASILEIRO DE FRUTICULTURA, 10., 1989, Fortaleza. Anais... Fortaleza: Sociedade Brasileira de Fruticultura, 1989. v. 1, p. 22-23.

SCOTT, A. J.; KNOTT, M. A cluster analysis method for grouping means in the analysis of variance. Biometrics, Washington, v. 30, p. 507512, Sept. 1974

SOUZA, C. de; NACHTIGAL, J.C.; KERSTEN, E. Efeito da lesão e do ácido indolbutírico no enraizamento de duas cultivares de ameixeira (Prunus salicina, Lindl) através de estaca. Revista Brasileira de Agrociência, Pelotas, v. 1, n. 3, p. 171-174, 1995. 